\title{
EFEITO DE EMBALAGENS, AMBIENTES E PERÍODOS DE ARMAZENAMENTO NA GERMINAÇÃO E NO VIGOR DAS SEMENTES DE CEDRO (Cedrela odorata) EM MANAUS - AM
}

\author{
Iza Maria Paiva Batista ${ }^{1}$, Antenor Francisco de Figueiredo ${ }^{2}$, Aldilane Mendonça da Silva ${ }^{3}$, \\ Têres Antônio Fabrício da Silva ${ }^{1}$ \\ ${ }^{1}$ Licenciada em Ciências Agrárias, M.Sc., UFAM, Manaus, AM, Brasil - im_paiva@ @otmail.com; teres180@yahoo.com.br \\ ${ }^{2}$ Eng. Agrônomo, Dr., Depto. de Produção Animal e Vegetal, UFAM, Manaus, AM, Brasil - antenor@ufam.edu.br \\ ${ }^{3}$ Licenciada em Ciências Agrárias, Mestranda em Ciências Florestais e Ambientais, UFAM, Manaus, AM, Brasil - aldileo01@ hotmail.com
}

Recebido para publicação: 11/02/2010 - Aceito para publicação: 05/07/2011

\begin{abstract}
Resumo
A conservação de sementes de espécies florestais é prática fundamental para o melhor aproveitamento da produção de mudas. Dessa forma, o objetivo deste estudo foi avaliar o efeito de diferentes embalagens, ambientes e períodos de armazenamento de Cedrela odorata L., na conservação da viabilidade e vigor das sementes. As sementes foram submetidas a três períodos de armazenamento (3, 6 e 9 meses) mais testemunha, acondicionadas em saco plástico e de papel, nas condições de geladeira e ambiente natural. $\mathrm{O}$ delineamento foi inteiramente casualizado em esquema fatorial, com cinco repetições de 20 sementes. Analisaram-se as seguintes variáveis: a porcentagem de germinação e a formação de plântulas normais. Os resultados indicaram que as sementes armazenadas na condição ambiente natural apresentaram redução drástica na germinação e na formação de plântulas normais ao longo dos períodos de armazenamento, enquanto na geladeira a redução foi menos intensa. Quanto ao tipo de embalagem, não foi constatado efeito, independentemente do ambiente de armazenamento. Concluiu-se que a condição geladeira foi eficiente para preservar a germinação e vigor das sementes de cedro.

Palavras-chave: Sementes florestais; viabilidade; condição de armazenamento; umidade; temperatura.
\end{abstract}

\begin{abstract}
Packages, environment and storage periods effects in germination and vigor of cedar (Cedrela odorata) seeds in Manaus, AM. Conservation of seeds of forest species is an important practice for the best use of seedlings production. According to that, this research aimed to evaluate effects of different packaging, environments and periods of storage of Cedrela odorata in conservation of viability and vigor of seeds. The seeds had been submitted to three periods of storage (3, 6 and 9 months) plus control, conditioned in plastic and paper, in refrigerator and natural environment conditions. The adopted delineation was entirely casualized in factorial scheme, with 5 repetitions of 20 seeds. It was analyzed the following variables: percentage of germination and formation of normal plantule. Results indicated that seeds stored in natural surrounding condition had presented drastic reduction in the germination and formation of normal plantule throughout storage periods, on the other hand, in refrigerator condition reduction had been less intense. In relation to the kind of packaging it was not identify any effect, independently of storage environment. It revealed that refrigerator conditions were efficient to preserve germination and vigor of cedar seeds.

Keywords: Forest seeds; viability; storage conditions; humidity; temperature.
\end{abstract}

\section{INTRODUÇÃO}

Cedrela odorata L. é uma espécie da família Meliaceae, que floresce nas matas de terra firme, sendo também frequente nas margens inundadas de alguns rios. Pode ser encontrada em toda a Amazônia e é frequente também no México, Peru, Equador e Guianas (SILVA, 2006). 
A árvore fornece madeira moderadamente pesada, muito resistente ao ataque de insetos, tida como sucedânea do mogno (Swietenia macrophylla King.), sendo de alto valor comercial e de larga utilização (LOUREIRO et al., 2000).

Segundo Silva (2006), essa espécie é indicada para a composição de reflorestamento heterogêneo, sistemas agroflorestais e recuperação de áreas degradadas, por apresentar rápido crescimento e bom rendimento nos plantios.

Apesar da importância da espécie, na Amazônia as pesquisas sobre sementes de espécies florestais nativas são insuficientes, principalmente no que se refere ao comportamento no armazenamento, com o intuito de manter a viabilidade por um período prolongado. Além disso, segundo Varela e Barbosa (1986/87), existem problemas resultantes da irregularidade de produção de sementes, da diversidade de espécies por área, da baixa frequência por área e dificuldade de acesso às árvores matrizes, as quais ocasionam, frequentemente, a falta de sementes. Esse conjunto de dificuldades limita o melhor aproveitamento dessas espécies em programas silviculturais.

$\mathrm{O}$ armazenamento de sementes permite a sua disponibilidade aos programas de reflorestamento e pesquisas sobre tecnologia e fisiologia de sementes. De modo geral, a conservação das sementes é de grande importância, uma vez que tem função básica de preservar a qualidade fisiológica das mesmas, sendo essa preservação possível porque o armazenamento, uma vez aplicado de modo adequado, vai diminuir a velocidade de deterioração, que se caracteriza por ser um processo irreversível (DELOUCHE et al., 1973; MELLO et al., 1998). Todavia, o sucesso do armazenamento depende do conhecimento prévio do comportamento fisiológico no armazenamento (HONG et al., 1996).

Diversos autores concordam que são muitos os fatores que afetam a longevidade das sementes durante o armazenamento. Conforme Toledo e Marcos Filho (1977), a longevidade das sementes é variável de acordo com as diferentes espécies, entretanto as condições de armazenamento também são um fator determinante para a manutenção da viabilidade. Segundo Lemos Filho e Duarte (2001), as condições de armazenamento das sementes influenciam na sobrevivência e na longevidade e, embora a qualidade dessas sementes não possa ser melhorada, ela pode ser mantida, dependendo das condições.

A embalagem é outro fator que tem grande influência na qualidade da semente durante o armazenamento. Quando são armazenadas em embalagens através das quais ocorrem trocas gasosas com a atmosfera, as sementes podem ganhar ou perder umidade, o que poderá influenciar a sua viabilidade. Toledo e Marcos Filho (1977) afirmam que a utilização de embalagens adequadas permite a conservação da qualidade das sementes. De acordo com Carneiro e Aguiar (1993), o uso da embalagem adequada e o controle do ambiente de armazenamento (temperatura e umidade relativa do ar), bem como do teor de água das sementes, podem aumentar a longevidade das sementes armazenadas artificialmente.

Diante dos fatos, observa-se que a temperatura e o tipo de embalagem de armazenamento têm grande influência na conservação da semente. Mas, para as sementes de cedro na região do Amazonas, os trabalhos disponíveis, além de escassos, não permitem o estabelecimento de tecnologias apropriadas de armazenamento. Desse modo, considerando a importância da espécie, há a necessidade de aprofundamento da busca de informações sobre o tema.

O objetivo deste trabalho foi avaliar o efeito de diferentes embalagens, ambientes e períodos de armazenamento de Cedrela odorata, visando à conservação da viabilidade e vigor das sementes para a utilização e comercialização em épocas em que não são produzidas.

\section{MATERIAL E MÉTODOS}

O experimento foi conduzido no laboratório de sementes I da Faculdade de Ciências Agrárias (FCA), situada no setor sul da Universidade Federal do Amazonas (UFAM), no período de setembro de 2006 a agosto de 2007, utilizando sementes obtidas a partir de frutos coletados de três árvores-matrizes distribuídas ao acaso na área, localizadas na Avenida André Araújo, próximo à garagem da prefeitura, na cidade de Manaus (AM). A colheita foi realizada na época de dispersão, quando foi observada a abertura espontânea dos frutos. Durante a coleta, foi utilizado podão para cortar os ramos. Em seguida, os frutos foram acondicionados em sacos de ráfia e transportados ao laboratório, onde foram colocados em bandejas para secagem natural, permanecendo até a liberação das sementes, que foram retiradas manualmente. 
Para os testes físicos (biometria, número de sementes por quilo, peso de mil sementes e teor de água), foram retiradas do lote amostras de sementes limpas e homogeneizadas (BRASIL, 1992). Para as medições, foi utilizado paquímetro digital com precisão de $0,01 \mathrm{~mm}$. Considerou-se como comprimento a medida da semente mais a aba; a largura, medida somente da região mais escura onde está localizada a semente; e a espessura, medida somente da região de localização da semente. Para cada uma das variáveis estudadas foram calculados a média aritmética e o erro padrão da média.

$\mathrm{Na}$ determinação do peso de 1000 sementes, utilizaram-se oito subamostras de 100 sementes puras. As subamostras foram pesadas, utilizando-se uma balança analítica com precisão de 0,001 g. calculou-se o coeficiente de variação para verificar se estava dentro do limite estabelecido (BRASIL, 1992). Baseado nos pesos das subamostras, foram calculadas as médias que, em seguida, foram multiplicadas por 10 (BRASIL, 1992). O número de sementes por quilograma foi determinado a partir do peso de 1000 sementes, de acordo com a seguinte fórmula (BRASIL, 1992):

$$
N^{\mathrm{a}} \text { de sementes } / \mathrm{kg}=\frac{1000}{\text { Peso de } 1000 \text { sementes }(\mathrm{g})} \times 1000
$$

$\mathrm{Na}$ determinação do teor de água das sementes, utilizaram-se duas repetições de 25 sementes inteiras colocadas em estufas à temperatura de $105^{\circ} \mathrm{C}$ por 24 horas, conforme recomendação da RAS (BRASIL, 1992). O teor de água foi determinado utilizando a seguinte fórmula:

$$
T A \%=\frac{100(P-p)}{P-t}
$$

em que: $\mathrm{P}=$ peso inicial; $\mathrm{p}=$ peso final; $\mathrm{t}=$ tara (peso do recipiente).

A determinação do teor de água das sementes foi realizada no início do experimento (umidade das sementes antes do armazenamento) e no final do experimento (umidade das sementes armazenadas em cada embalagem e em cada ambiente).

Os testes de germinação das sementes foram conduzidos em germinador tipo Mangelsdorf, com a umidade relativa próxima a $100 \%$ e temperatura de $30{ }^{\circ} \mathrm{C}$. Como recipiente, foi utilizado o gerbox $(11 \times 11 \times 3,2 \mathrm{~cm})$, contendo como substrato papel filtro previamente autoclavado.

Antes do procedimento de instalação do teste, as sementes foram lavadas com hipoclorito de sódio a $1 \%$ durante 2 minutos e, em seguida, enxaguadas em água corrente. A cada três dias efetuou-se a avaliação do número de sementes germinadas, por um período de 40 dias após a semeadura. Periodicamente, durante a avaliação da germinação e dependendo da necessidade, foi borrifada água destilada, a fim de manter o substrato sempre úmido.

Para avaliar o efeito do armazenamento, o delineamento empregado foi o inteiramente casualizado, em arranjo fatorial, cujos tratamentos foram: três períodos de armazenamento $(3,6,9$ meses); duas condições de armazenamento: geladeira (temperatura de 7 a $8{ }^{\circ} \mathrm{C}$ e 78 a $80 \%$ de umidade relativa) e ambiente natural (temperatura de 24 a $26{ }^{\circ} \mathrm{C}$ e 70 a $80 \%$ de umidade relativa); e dois tipos de embalagens: saco plástico $(0,10 \mathrm{~mm})$ e saco de papel (semikraft), mais uma testemunha (tratamento adicional - sementes não armazenadas). Os tratamentos foram distribuídos em cinco repetições de 20 sementes cada.

Ao final do período de ensaio, as seguintes características foram avaliadas: porcentagem total de sementes germinadas, adotando-se como critério de germinação a protrusão de $2 \mathrm{~mm}$ de radícula (LABOURIAU, 1983) e a formação de plântulas normais, conforme Brasil (1992).

A análise estatística foi feita empregando-se o programa estatístico Sistema de Análises Estatísticas e Genéticas (SAEG). Anteriormente às análises estatísticas, os dados de porcentagem de germinação foram submetidos ao teste de normalidade de Lilliefors (LILLIEFORS, 1967) e, quando necessário, à transformação em $\sqrt{ }(\mathrm{x}+0,5)$. Em seguida foram submetidos à análise de variância e as médias comparadas pelo teste de Tukey a 5\% de probabilidade. Quando houve efeito de interação entre os fatores, fez-se o desdobramento para cada embalagem e ambiente em função do período de armazenamento. Para os períodos de armazenamento, utilizando os dados originais, foram ajustadas equações com o auxílio do programa Microsoft Excel (NASCIMENTO, 2007). 


\section{RESULTADOS E DISCUSSÃO}

\section{Características físicas}

As sementes são samaroides, apresentando em média $49 \mathrm{~mm}$ de comprimento (incluindo a asa), $5 \mathrm{~mm}$ de largura e $1 \mathrm{~mm}$ de espessura (Tabela 1). Rocas (2003) verificou resultados semelhantes, com média de 2 a $3 \mathrm{~cm}$ de comprimento, 3,5 a $5 \mathrm{~mm}$ de largura e 1,2 a 1,5 $\mathrm{mm}$ de espessura para a mesma espécie.

Tabela 1. Dados biométricos das sementes $(\mathrm{n}=100)$ de Cedrela odorata.

Table 1. Biometric Cedrela odorata seeds $(\mathrm{n}=100)$.

\begin{tabular}{lc}
\hline Especificação & Semente \\
\cline { 2 - 2 } & Média \pm EPM \\
\hline Comprimento $(\mathrm{mm})$ & $49,399 \pm 2,965$ \\
Largura (mm) & $5,908 \pm 0,670$ \\
Espessura $(\mathrm{mm})$ & $1,279 \pm 0,158$ \\
Peso de 1000 sementes $(\mathrm{g})$ & 50 \\
Número de sementes por kg & 20.000 \\
\hline EPM: erro padrão da média de 100 sementes.
\end{tabular}

Em média, 50 g continham 20.000 sementes, com 39,7\% de umidade. Esses resultados diferem dos encontrados por Silva (2006), que foi em média de 56.338 sementes em lotes com 11,05\% de umidade.

A umidade das sementes de Cedrela odorata teve oscilações em função do ambiente de armazenamento, sobretudo do tipo de embalagem utilizada. As sementes armazenadas em saco de papel, tanto na condição ambiente natural como em geladeira, apresentaram redução do grau de umidade quando comparadas com a umidade inicial (Tabela 2). Corvello et al. (1999) observaram que o teor de água das sementes de Cedrela fissilis armazenadas em saco de papel aumentou com o tempo de armazenamento, tanto em ambiente refrigerado como no ambiente natural. Essa redução deve-se ao tipo de embalagem utilizada, pois ela permite uma livre troca de vapor d'água entre as sementes e o ambiente circundante (GARCIA; LIMA, 2000).

Tabela 2. Grau de umidade $(\%)$ de sementes de Cedrela odorata no período inicial $\left(\mathrm{P}_{0}\right)$ e final $\left(\mathrm{P}_{3}\right)$, acondicionadas em diferentes embalagens e ambientes, em Manaus (AM).

Table 2. Degree of humidity $(\%)$ of Cedrela odorata seeds in the initial period $\left(\mathrm{P}_{0}\right)$ and end $\left(\mathrm{P}_{3}\right)$, conditioned in different packings and environments, in Manaus (AM).

\begin{tabular}{lccc}
\hline \multirow{2}{*}{ Embalagem } & \multirow{2}{*}{ Ambiente (temperatura) } & \multicolumn{2}{c}{ Período de armazenamento (meses) } \\
\cline { 3 - 4 } & & $\mathbf{0}$ & $\mathbf{9}$ \\
\hline Saco plástico & Geladeira & 39,7 & 44,3 \\
& Ambiente natural & 39,7 & 42,7 \\
\hline Saco de papel & Geladeira & 39,7 & 33,2 \\
& Ambiente natural & 39,7 & 22,1 \\
\hline
\end{tabular}

$\mathrm{P}_{0}$ : testemunha; $\mathrm{P}_{3}: 9$ meses de armazenamento.

Quanto à embalagem saco plástico, nota-se o oposto: as sementes obtiveram ganho de água, independentemente do ambiente em que foram mantidas (Tabela 2), sendo que os teores de água permanecem próximos aos das sementes frescas. Esse fato deve-se à impermeabilidade conferida pelo plástico à embalagem, impedindo que a umidade das sementes atingisse o equilíbrio com a umidade do ambiente, concordando com Nery (2006) ao afirmar que a utilização da embalagem de saco de plástico na conservação de guanandi (Calophyllum brasiliense Cambess) atenua a redução do grau de umidade ao longo do tempo de armazenamento.

Da mesma forma, Kano et al. (1978) descrevem para as sementes da espécie ipê (Tabebuia sp.) que o teor de umidade das sementes acondicionadas em sacos plásticos aumenta lenta e gradativamente no transcorrer do período de armazenamento, tanto em câmara fria quanto em ambiente natural. 


\section{Influência dos tratamentos na germinação das sementes de cedro}

Analisando as curvas ajustadas para a germinação (Figura 1A), observa-se um decréscimo com efeito polinomial de segundo grau nas sementes acondicionadas na condição de geladeira, com o ponto de inflexão (valor mínimo) em torno de $89,5 \%$ de germinação atingida no quinto mês de armazenamento. Em geral, o potencial germinativo das sementes de $C$. odorata teve uma pequena diminuição com o tempo de armazenamento, sendo que as sementes acondicionadas em saco plástico obtiveram um menor declínio de germinação que a embalagem de papel. Certamente, a combinação da temperatura baixa com a umidade relativa do ar alta juntamente com a embalagem de plástico (semipermeável) proporcionou condições mais favoráveis, o que minimizou a velocidade de deterioração das sementes. Esses resultados estão de acordo com Toledo e Marcos Filho (1977), para quem a longevidade da semente armazenada pode variar quando se empregam diferentes tipos de embalagem, em razão da troca de umidade.

Segundo Labouriau (1983), o armazenamento visa manter a semente em criptobiose, ou seja, num estado de parada do crescimento do embrião, pela redução do metabolismo ativo. O resultado obtido na condição de geladeira demonstra que o armazenamento nessas condições manteve sua capacidade de geminar por maiores períodos, mesmo que em níveis inferiores ao inicial.

$\mathrm{Na}$ condição ambiente natural, as curvas ajustadas revelam que as sementes de cedro tiveram uma queda acentuada na germinação, independentemente do tipo de embalagem (Figura 1B), com valores de germinação condicionados pelos períodos de armazenamento, alcançando valor zero já no quarto mês de armazenamento. Embora as sementes de cedro tenham sido armazenadas com 39,7\% de umidade, considerado alto para espécies ortodoxas (BONNER, 1989), a velocidade de perda de germinação foi similar ao observado para Cedrela angustifolia, armazenada em ambiente de laboratório, com grau de umidade inicial de 18,3\% (PIÑA-RODRIGUES; JESUS, 1992). Fowler e Carpanezzi (1998a) também relataram que o armazenamento em sala de laboratório (ambiente não controlado) de sementes de angicogurucaia (Parapiptadenia rígida (BENTHAM) BRENAN) foi desfavorável para a manutenção da viabilidade antes dos 12 meses de armazenamento.

No que diz respeito à porcentagem de plântulas normais, foram observadas tendências semelhantes à porcentagem de germinação (Figuras 1C e 1D). Embora apresentando comportamento semelhante, a formação de plântulas normais apresentou taxas inferiores a partir da testemunha, sugerindo que o lote de sementes apresentava sementes pouco vigorosas, ou seja, com baixa qualidade inicial. Segundo Carvalho e Nakagawa (2000), o vigor das sementes tem consequências importantes no armazenamento delas, pois quanto menor o vigor, mais baixo será o potencial de armazenamento.

Vale ressaltar que, mesmo quando mantidas sob as melhores condições, as sementes de $C$. odorata tiveram a formação de plântulas normal reduzida drasticamente, quando comparada com os valores iniciais, alcançando média inferior a 50\% a partir do terceiro mês de armazenamento (Figura 1C). O ponto de inflexão (valor mínimo) em torno de $29,2 \%$ foi alcançado aproximadamente no quarto mês de armazenamento na embalagem de plástico e em torno de 6,1\% atingida no décimo quarto mês de armazenamento na embalagem de papel. $\mathrm{O}$ fato de as sementes terem sido embaladas com o grau de umidade inicial alto (Tabela 2) pode também ter contribuído para que a queda no vigor fosse acentuada nessas condições. Esses resultados quanto às embalagens de armazenamento assemelham-se aos obtidos por Varela e Barbosa (1986/1987) para sementes de cedrorana (Cedrelinga catenaeformis Ducke).

Quando armazenadas na condição ambiente natural, as sementes apresentaram declínio do vigor similar para as duas embalagens, conforme verificado na formação de plântulas normais (Figura 1D). Dessa forma, pode-se constatar que o ambiente exerceu maior influência que a embalagem sobre a conservação das sementes, de modo que, a partir do terceiro mês de armazenamento, as sementes mantidas em ambiente natural, independentemente da embalagem, tiveram seu vigor reduzido significativamente. Da mesma forma, Souza et al. (2005) constataram que as sementes de ipê-amarelo (Tabebuia serratifolia (Vahl) Nichols.) mantidas em refrigerador apresentaram menor redução no vigor ao longo do armazenamento, quando comparada àquelas armazenadas no laboratório (condições naturais). Segundo Vieira e Carvalho (1994), o processo de deterioração das sementes durante o armazenamento ocasiona uma queda progressiva na porcentagem de plântulas normais. Essas condições aumentam as atividades respiratórias das sementes e reduzem a sua qualidade, como consequência do esgotamento de suas reservas (CARNEIRO; AGUIAR, 1993).

$\mathrm{Na}$ tabela 3 estão expressos os resultados de germinação e plântulas normais das sementes de cedro para os fatores tipo de embalagem, condição de ambiente e período de armazenamento. 

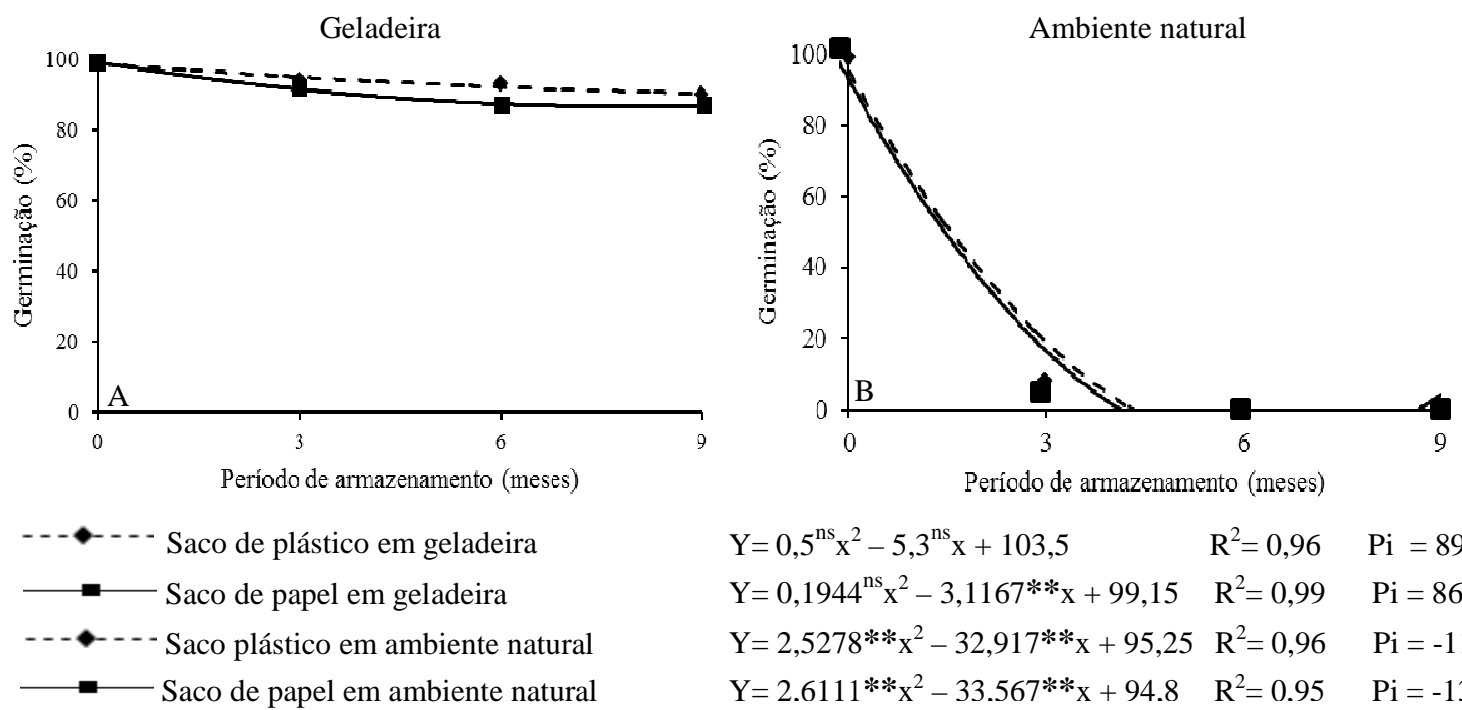

$$
\begin{array}{lll}
\mathrm{Y}=0,5^{\mathrm{ns}} \mathrm{x}^{2}-5,3^{\mathrm{ns}} \mathrm{x}+103,5 & \mathrm{R}^{2}=0,96 & \mathrm{Pi}=89,5 \\
\mathrm{Y}=0,1944^{\mathrm{ns}} \mathrm{x}^{2}-3,1167 * * \mathrm{x}+99,15 & \mathrm{R}^{2}=0,99 & \mathrm{Pi}=86,7 \\
\mathrm{Y}=2,5278 * x^{2}-32,917 * * \mathrm{x}+95,25 & \mathrm{R}^{2}=0,96 & \mathrm{Pi}=-11,9 \\
\mathrm{Y}=2.6111^{2} \mathrm{x}^{2}-33.567 * * \mathrm{x}+94.8 & \mathrm{R}^{2}=0.95 & \mathrm{Pi}=-13.1
\end{array}
$$
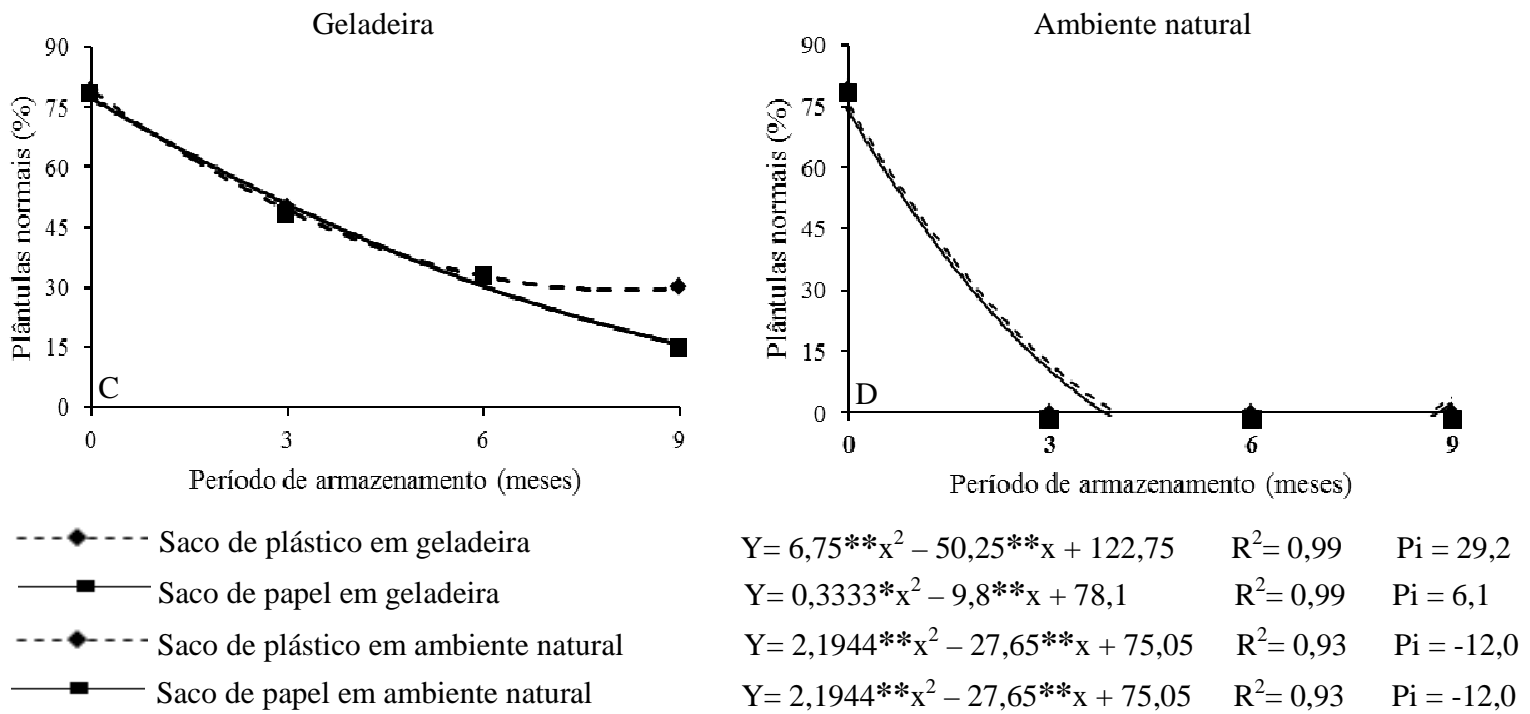

Figura 1. Germinação de sementes e a produção de plântulas normais de Cedrela odorata, acondicionadas em diferentes embalagens e condições ao longo de quatro períodos de armazenamento ( $\mathrm{x}$, em meses). ns: não significativo; * e **: significativo a $5 \%$ e $1 \%$ de probabilidade; Pi: ponto de inflexão.

Figure 1. Germination of seeds and the normal production of plantule of Cedrela odorata, conditioned in different packings and environment condition throughout four periods of storage (x, in months). ns: not significant; * and **: significant 5 and $1 \%$ of probability; ip: inflection point.

Analisando o fator condição de armazenamento, verificou-se que houve diferenças significativas na germinação e no vigor das sementes para as duas condições estudadas, o que se confirma nas análises dos valores absolutos (Figura 1). Conforme as análises, a condição geladeira apresentou-se mais favorável do que a condição de ambiente natural. O armazenamento em geladeira proporcionou menor redução na germinação e no vigor, estando de acordo com Floriano (2004), o qual relata que condições de baixa temperatura são as mais recomendadas para armazenar sementes ortodoxas. 
Tabela 3. Percentagens médias de germinação e plântulas normais obtidas de sementes de Cedrela odorata armazenadas em condição de geladeira e ambiente natural, acondicionadas em sacos de polietileno e em sacos de papel, durante quatro períodos de armazenamento.

Table 3. Mean percentages of germination and normal plantule obtained of Cedrela odorata seeds stored in condition of refrigerator and natural environment, conditioned in polyethylene bags and bags of paper, during four periods of storage.

\begin{tabular}{lccc}
\hline Tratamentos & & Germinação (\%) & Plântulas normais (\%) \\
\hline Ambiente: & Geladeira & $92 \mathrm{a}$ & $41 \mathrm{a}$ \\
& Natural & $16 \mathrm{~b}$ & $11 \mathrm{~b}$ \\
\hline Embalagem: & Plástico & 60 & 34 \\
& Papel & 59 & 32 \\
\hline Período: & 0 & $99 \mathrm{a}$ & $79 \mathrm{a}$ \\
& 3 & $50 \mathrm{~b}$ & $25 \mathrm{~b}$ \\
& 6 & $45 \mathrm{c}$ & $16 \mathrm{c}$ \\
& 9 & $44 \mathrm{c}$ & $11 \mathrm{~d}$ \\
\hline
\end{tabular}

Período: dado em meses. Obs.: As médias seguidas pela mesma letra não diferem estatisticamente entre si pelo teste de Tukey, ao nível de 5\% de probabilidade.

Apesar de as embalagens utilizadas apresentarem diferentes características com relação às trocas de vapor d'água, elas comportaram-se de maneira semelhante nas duas condições de ambiente, ou seja, de acordo com os resultados das análises dos valores de germinação e de vigor (Tabela 3) não houve diferenças significativas entre as duas embalagens, sendo que a embalagem de plástico teve ligeira superioridade à embalagem de papel na condição de geladeira, como pode se observar nos valores absolutos (Figura 1A e 1C). Matos et al. (2008) também não verificaram diferenças para as embalagens papel e polietileno no armazenamento de pente-de-macaco (Apeiba tibourbou GAERTN.) na condição de ambiente não controlado, enquanto que na condição ambiente controlado a embalagem polietileno se apresentou mais adequada para a conservação de sua viabilidade.

Analisando o período de armazenamento, observa-se que houve redução da germinação e vigor das sementes, fato este verificado também para outras espécies (FOWLER; CARPANEZZI, 1998b; MEDEIROS; ZANON, 1998a; DEGAN et al., 2001; SANTOS; CESAR DE PAULA, 2007). A figura 1 ilustra o desempenho da germinação e do vigor no decorrer do armazenamento, comprovando as afirmações de Delouche et al. (1973) de que a deterioração é inevitável e irreversível, sendo a velocidade das transformações degenerativas dependente das condições nas quais a semente foi exposta antes e após a colheita.

Tabela 4. Interação período de armazenamentos x ambiente sobre a germinação e produção de plântulas normais obtidas de sementes de Cedrela odorata.

Table 4. Period of storage interaction $\mathrm{x}$ environment on the germination and production of normal plantule obtained of Cedrela odorata seeds.

\begin{tabular}{|c|c|c|c|c|}
\hline \multirow{2}{*}{$\begin{array}{l}\text { Período } \\
\text { (meses) }\end{array}$} & \multicolumn{2}{|c|}{ Germinação (\%) } & \multicolumn{2}{|c|}{ Plântulas normais (\%) } \\
\hline & Geladeira & Ambiente & Geladeira & Ambiente \\
\hline 0 & $99 \mathrm{~A} \mathrm{ab}$ & $99 \mathrm{~A} a b$ & $79 \mathrm{~A} \mathrm{a}$ & $79 \mathrm{~A} \mathrm{a}$ \\
\hline 3 & $93 \mathrm{~A} \mathrm{ab}$ & $6 \mathrm{~B} \mathrm{~b}$ & $49 \mathrm{~A} \mathrm{~b}$ & $0 \mathrm{~B} \mathrm{~b}$ \\
\hline 6 & $90 \mathrm{~A} \mathrm{ab}$ & $0 \mathrm{~B} \mathrm{cb}$ & $33 \mathrm{Ac}$ & $0 \mathrm{~B} \mathrm{~b}$ \\
\hline 9 & $88 \mathrm{~A} \mathrm{~b}$ & $0 \mathrm{~B} \mathrm{c}$ & $23 \mathrm{Ad}$ & $0 \mathrm{~B} \mathrm{~b}$ \\
\hline
\end{tabular}

Obs.: Letras maiúsculas nas linhas comparam ambientes dentro de cada período de armazenamento e letras minúsculas nas colunas comparam médias dentro de cada período de armazenamento, pelo teste de Tukey a 5\% de probabilidade.

Constatou-se, através dos resultados da tabela 4, perda acentuada na viabilidade das sementes armazenadas no ambiente natural, com valores nulos no quarto mês de armazenamento, sendo o ponto de inflexão atingido abaixo desse tempo, em torno de seis meses de armazenamento (Figura 1B e 1D). Possivelmente, essa ocorrência deve estar associada às oscilações de temperatura e umidade no ambiente natural, que têm influência direta sobre a semente devido à sua higroscopicidade. Medeiros e Zanon (1998b) relatam que a perda de qualidade fisiológica das sementes armazenadas em condições ambientais pode ser devida à variação da umidade e da temperatura do ambiente e à proliferação de fungos de 
armazenamento. A ação desses microrganismos, desde que haja condições de umidade e temperatura, pode, conforme Carvalho e Nakagawa (2000), acelerar a taxa de deterioração das sementes.

$\mathrm{O}$ ambiente de geladeira manteve os mesmos níveis de germinação inicial até o final do experimento. Essas observações indicam ser conveniente o armazenamento das sementes dessa espécie sob refrigeração, em decorrência provavelmente das condições mais favoráveis de temperatura e umidade da geladeira. Esses resultados são confirmados também por Scalon et al. (2004), que encontraram resultado similar para uvaia (Eugenia uvalha Cambess.) e chegaram a recomendar o armazenamento da espécie por 90 dias sob refrigeração. Santana e Carvalho (2006) relataram, em seu trabalho, que as sementes de carqueja (Baccharis trimera (Less) DC.) acondicionadas em geladeira apresentaram melhor conservação independentemente da embalagem utilizada. Quanto à formação de plântulas normais, a partir dos três meses de armazenamento ocorreu uma queda nesse índice, indicando que, quanto mais tempo as sementes de cedro permanecerem armazenadas, mais haverá redução no vigor, o que pode ser explicado pelo avanço no processo de deterioração. Segundo Vieira e Carvalho (1994), o processo de deterioração das sementes durante o armazenamento ocasiona uma queda progressiva na porcentagem de plântulas normais. Os resultados observados neste trabalho são similares aos obtidos por Nery (2006), que, estudando o armazenamento de sementes de Calophyllum brasiliense, observou queda acentuada no vigor das sementes ao longo do armazenamento. Pontes et al. (2006), da mesma forma, em estudo da influência da temperatura de armazenamento na qualidade das sementes de sibipiruna (Caesalpinia peltophoroides Benth.), verificaram redução significativa no vigor das sementes com o aumento do tempo de armazenamento.

\section{CONCLUSÕES}

- A condição mais favorável para o armazenamento de sementes de cedro, por até nove meses, foi a de geladeira.

- As embalagens de papel e plástico tiveram influência semelhante na conservação das sementes tanto na condição de geladeira como de ambiente.

- Independentemente do ambiente e/ou embalagem de acondicionamento, a qualidade fisiológica das sementes tende a reduzir ao longo do período de armazenamento.

- O armazenamento de sementes de Cedrela odorata em geladeira ou câmera fria é recomendado. No entanto, as sementes devem ser armazenadas com menores teores de umidade, o que deve proporcionar períodos mais longos de armazenamento.

\section{REFERÊNCIAS}

BONNER, F. T. Tropical forest seeds: biology, quality and technology. In: SIMPÓSIO BRASILEIRO SOBRE TECNOLOGIA DE SEMENTES FlORESTAIS, 2., 1989, Atibaia, Anais... Atibaia, SP, 1989. p. $263-274$.

BRASIL. Regras para análise de sementes. Ministério da Agricultura e Reforma Agrária, Brasília, Distrito Federal, 1992. 365 p.

CARNEIRO, J. G. A.; AGUIAR, I. B. Armazenamento de sementes. In: AGUIAR, I. B.; PIÑARODRIGUES, F. C. M.; FIGLIOLIA, M. B. Sementes florestais tropicais. ABRATES, 1993. p. 333 - 350.

CARVALHO, N. M.; NAKAGAWA, J. Sementes: ciência, tecnologia e produção. 4. ed. Jaboticabal: FUNEP, 2000. 588 p.

CORVELlO, W. B. V.; VILlELA, F. A.; NEDEL, J. L.; PESKE, S. T. Época de colheita e armazenamento de cedro (Cedrela fissilis Vell.). Revista Brasileira de Sementes, v. 21, n. 2, p. 28 - 34, 1999.

DEGAN, P.; AGUIAR, I. B. de; SADER, R.; PERECIN, D.; PINTO, L. R. Influência de métodos de secagem na conservação de sementes de ipê-branco. Revista Brasileira de Engenharia Agrícola e Ambiental, v. 5, n. 3, p. 492 - 496, 2001. 
DELOUCHE, J. C.; MATHEUS, R. K.; DOUGUERTY, G. M.; BOYD, A. H. Storage of seed in sub-tropical regions. Seed Science and technology, v. 1, n. 3, p. 671 - 700, 1973.

FLORIANO, E. P. Armazenamento de sementes florestais. Santa Rosa, 2004. 10 p. (Caderno didático n. 1).

FOWLER, J. A. P.; CARPANEZZI, A. A. Conservação de sementes de angico-gurucaia (Parapiptadenia rígida (Bentham.) Brenan). Boletim de Pesquisa Florestal, n. 36, p. 5 - 10, 1998a.

Conservação de sementes de juquiri (Mimosa regnellii Bentham.). Boletim de Pesquisa Florestal, n. 36, p. 41 - 46, 1998b.

GARCIA, L. C.; LIMA, D. de. Comportamento de sementes de Copaifera multijuga durante o armazenamento. Acta Amazonica, v. 30, n. 3, p. 369 - 375, 2000.

HONG, T. D.; LININGTON, S.; ELLIS, R. H. Seed storage behaviour: a compendium. Rome: International Plant Genetic Resources Institute, 1996. 656 p. (Handbooks for Genebanks, n. 4).

KANO, N. K.; MACHADO MÁRQUEZ, F. C.; KAGEYAMA, P. Y. Armazenamento de sementes de ipê-dourado (Tabebuia sp.). Instituto de Pesquisas e Estudos Florestais, n. 17, p. 13 - 23, 1978.

LABOURIAU, L. G. A germinação de sementes. Washington: Secretaria Geral da Organização dos Estados Americanos, OEA, 1983. 174 p.

LEMOS FILHO, J. P.; DUARTE, R. J. Germinação e longevidade das sementes de mogno (Swietenia macrophylla King - Meliaceae). Revista Árvore, v. 25, n. 1, p. 125 - 130, 2001.

LILLIEFORS, H. W. On the Kolmogorov-Smirnov test for normality with mean and variance unknownown. Journal of the American Statistics Association, Boston, v. 62, p. 399 - 402, 1967.

LOUREIRO, A. A.; FREITAS, J. A. de; RAMOS, K. B. L.; FREITAS, C. A de. Essências madeireiras da Amazônia. Manaus: INPA, 2000. v. 4.191 p.

MATOS, V. P.; FERREIRA, E. G. B. de S.; FERREIRA, R. L. C.; SENA, L. H. de M.; SALES, A. G. de F. A. Efeito do tipo de embalagem e do ambiente de armazenamento sobre a germinação e o vigor das sementes de Apeiba tibourbou Aubl. Revista Árvore, v. 32, n. 4, p. 617 - 625, 2008.

MEDEIROS, A. C. de S.; ZANON, A. Conservação de sementes de branquilho (Sebastiania commersoniana (Baillon) L. B. Smith e R. J. Down) e de pinheiro-bravo (Podocarpus lambertii Klotzch ex e NDL.), armazenadas em diferentes ambientes. Boletim de Pesquisa Florestal, n. 36, p. 57 - 69, 1998a.

Conservação de sementes de aroeira-vermelha (Schinus terebinthifolius RADDI). Boletim de Pesquisa Florestal, n. 36, p. 11 - 20, 1998 b.

MELlO, J. T.; SILVA, J. A.; TORRES, R. A. A.; SIVEIRA, C. E. S.; CALDAS, L. S. Coleta, propagação e desenvolvimento inicial de espécies do Cerrado. In: Cerrado: ambiente e flora. SANO, S. M.; ALMEIDA, S. P. (Ed.). Distrito Federal: Embrapa, 1998. 556 p.

NASCIMENTO, M. D. C. Substrato e recipientes para produção de mudas e análise de crescimento de paricá (Schizolobium amazonicum Huber ex. Ducke). 69 f. Dissertação (Mestrado em Ciências Florestais e Ambientais) - Universidade Federal do Amazonas, Manaus, 2007.

NERY, F. C. Aspectos da germinação, armazenamento de sementes, crescimento inicial e anatomia de plantas jovens de (Calophyllum brasiliense Cambess.). 173 f. Dissertação (Mestrado em Agronomia) - Universidade Federal de Lavras, Lavras, 2006.

PIÑA-RODRIGUES, F. C. M.; JESUS, R. M. de. Comportamento das sementes de cedro-rosa (Cedrela angustifolia S. ET. MOC) durante o armazenamento. Revista Brasileira de Sementes, v. 14, n. 1, p. 31 36, 1992. 
PONTES, C. A.; CORTE, V. B.; BORGES, E. E. de L.; SILVA, A. G. da; BORGES, R. de C. G. Influência da temperatura de armazenamento na qualidade das sementes de Caesalpinia peltophoroides Benth. (Sibipiruna). Revista Árvore, v. 30, n. 1, p. 43 - 48, 2006.

ROCAS, A. N. Cedrela odorata L. In: Tropical tree seed manual: species descriptions. Vera Cruz: Instituto de Ecologia, 2003. p. 386 - 389.

SANTANA, A. de M. S.; CARVALHO, R. I. N. de. Viabilidade e capacidade de armazenamento de sementes de carqueja coletadas em três municípios no Paraná. Scientia Agraria, v. 7, n. 1/2, p. 15 - 20, 2006.

SANTOS, S. R. G. dos; CESAR DE PAULA, R. Qualidade fisiológica de sementes de Sebastiania commersoniana (Baill.) Smith e Downs (branquilho - Euphorbiaceae) durante o armazenamento. Scientia Forestalis, n. 74, p. 87 - 94, 2007.

SCALON, S. P. Q.; SCALON FILHO, H.; RIGONI, M. R. Armazenamento e germinação de sementes de uvaia Eugenia uvalha Cambess. Ciência Agrotécnica, v. 28, n. 6, p. 1228 - 1234, 2004.

SILVA, S. Árvores da Amazônia. São Paulo: Empresa das Artes, 2006. 244 p.

SOUZA, V. C. de; ALCÂNTARA BRUNO, R. de L.; ANDRADE, L. A. Vigor de sementes armazenadas de ipê-amarelo Tabebuia serratifolia (Vahl.) Nich. Revista Árvore, v. 29, n. 6, p. 833 - 841, 2005.

TOLEDO, F. F.; MARCOS FILHO, J. Manual de sementes: tecnologia da produção. São Paulo: Agronômica Ceres, 1977. 224 p.

VARELA, V. P.; BARBOSA, A. P. Conservação de sementes de cedrorana (Cedrelinga catenaeformis Ducke) Leguminosae. Acta Amazonica, v. 16/17, n. único, p. 549 - 555, 1986/87.

VIEIRA, R. D.; CARVALHO, N. M. Testes de vigor em sementes. Jaboticabal: FUNEP, 1994. 164 p. 